\title{
OPEN DISLOGATION OF THE ELBOW WITH RUPTURE OF THE BRACHIAL ARTERY
}

\author{
Robert S. Henderson, Edmonton, Alberta, Canadi, and \\ Ivor M. Robertson, LONdon, ENGLAND \\ From the Orthopaedic Department, St Bartholomew's Hospital
}

A search of the literature has revealed only one report in Britain of posterior dislocation of the elbow complicated by rupture of the brachial artery. This was a closed injury (Marnham 1934). In America, Cotton (1924) described the complication of arterial rupture as "excessively rare and compound mainly." Eliason and Brown (1937) collected twenty-one case records of posterior dislocation of the elbow with arterial damage. Sixteen of these were open injuries and in fifteen the brachial artery was found divided. In the remainder, the

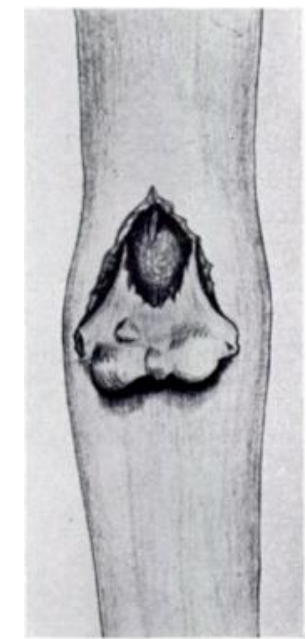

FIG. 1

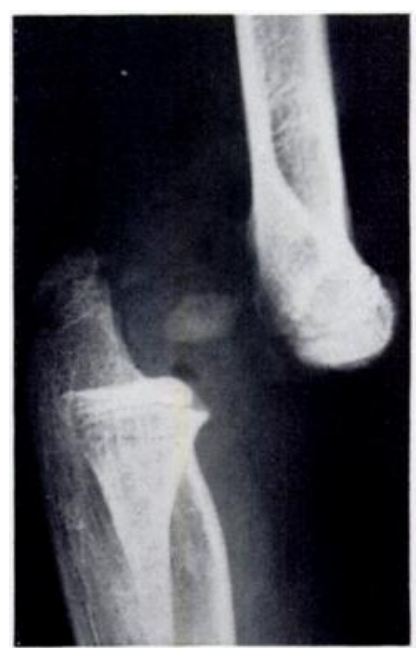

FIG. 2

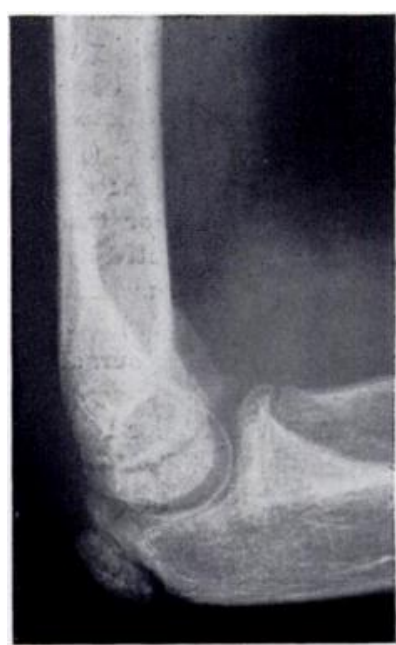

Fig. 3

Case 1. Figure 1-Drawing of elbow before operation. Figure 2-Radiograph before operation. Posterior dislocation of elbow with detachment of medial epicondyle. Figure 3-Condition one month after operation.

radial and ulnar arteries were ruptured. Out of these twenty-one cases, only five gave good functional results. This paper reports two cases of open posterior dislocation with arterial rupture, one of which was further complicated by closed fractures of both bones of the forearm.

Case 1-A boy aged thirteen years was admitted after a fall from a gymnastic " horse." His general condition was good. The left elbow was held fully extended and, protruding through a small wound in the antecubital fossa, was seen the lower end of the humerus, denuded of all soft tissues (Fig. 1). The hand was pale and cold, and pulses at the wrist could not be felt. Radiographs showed, in addition to posterior dislocation of the elbow, a fracture of the medial epicondyle (Fig. 2). At operation, the edges of a small longitudinal wound were excised and the opening extended proximally and distally. Lying in front of the retracted brachialis muscle, the proximal cut end of the brachial artery was found sealed off and pulsating. The distal cut end was found lying under cover of the humerus. Both were ligated. The ulnar nerve lay across the olecranon fossa. Median and radial nerves were not seen. By combined flexion of the elbow and traction on the forearm the dislocation 
was reduced (Fig. 3). The ulnar nerve was transposed anteriorly and the medial epicondyle, with its attached flexor origin, was reattached with a few sutures and the wound closed.

After operation, radial and ulnar pulses returned within forty-eight hours. A partial wrist drop recovered in less than two weeks. After four weeks, active movements were begun. One year later elbow movements and power were full.

Case 2-A boy aged nineteen years was admitted after a fall from a tree on to his outstretched right hand. From a ragged, transverse wound in front of his right elbow was seen protruding the lower end of the humerus. In the forearm, the clinical appearance of closed fractures of radius and ulna, at junction of lower and middle thirds, was confirmed by radiographs (Fig. 4). Pulses could not be felt at the wrist. At operation the wound was excised. The only structure lying in front of the humerus was identified as the median nerve. The cut ends of the brachial artery, separated by a gap of four centimetres, were found under the wound edges and ligated. The ulnar nerve was not seen. The dislocation was reduced and the wound closed. An attempt to reduce the forearm fractures by manipulation was rendered difficult by the instability of the elbow. Circulation returned to the hand within fortyeight hours and there were no signs of median or ulnar nerve injury. Three weeks later, open reduction of the forearm fractures was carried out, fixation being maintained by stainless steel plates. Immobilisation by plaster was deferred, and active movements of the elbow were encouraged for three weeks. Then a close-fitting full arm plaster was applied. After ten weeks

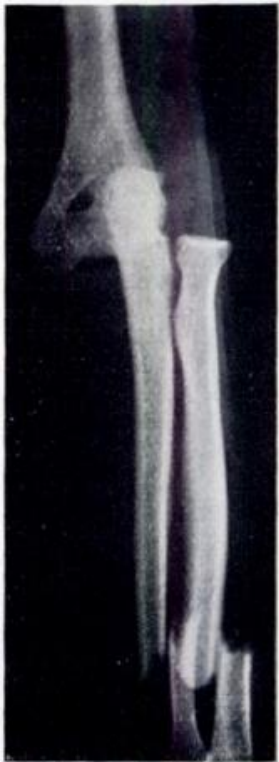

FIG. 4

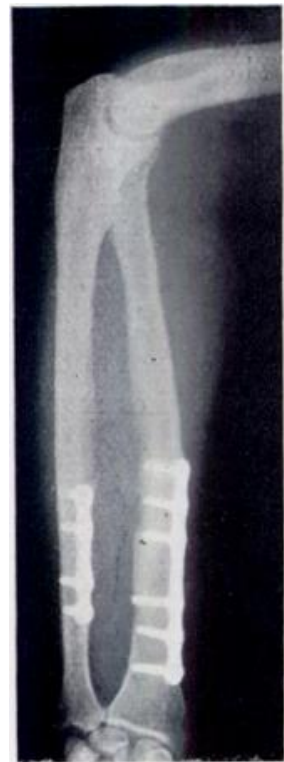

Fig. 5

Case 2. Figure 4-Before operation. Dislocation of elbow with fractures of radius and ulna. Figure 5-Condition one year after operation. both fractures had united and active movements were resumed. The condition one year after the injury is shown in Figure 5. Movements and power of elbow and wrist were almost full.

We should like to thank Mr S. L. Higgs for permission to publish the first case, Dr W. J. Wright for his drawing at operation and Mr R. G. Whitley of the Institute of Orthopaedics for his help with the reproductions.

\section{REFERENCES}

Cotton, F. J. (1924): Dislocations and Joint Fractures. Second edition. Philadelphia and London: W. B. Saunders Company.

Eliason, E. L., and Brown, R. B. (1937): Posterior Dislocation at the Elbow with Rupture of Radial and Ulnar Arteries. Annals of Surgery, 106, 1111.

MARnham, R. (1934): Dislocation of Elbow with Rupture of the Brachial Artery. British Journal of Surgery, 22, 181.

vol. $34 \mathrm{~B}$, No. 4, vovember 1952

$$
\mathbf{G}_{(\varepsilon)}
$$

